\title{
Patient safety, satisfaction, and quality of hospital care: cross sectional surveys of nurses and patients in 12 countries in Europe and the United States
}

\author{
Linda H Aiken professor and director ${ }^{1}$, Walter Sermeus professor and director ${ }^{2}$, Koen Van den \\ Heede health services research expert ${ }^{17}$, Douglas M Sloane professor ${ }^{1}$, Reinhard Busse professor \\ and director ${ }^{3}$, Martin McKee professor ${ }^{4}$, Luk Bruyneel research fellow ${ }^{2}$, Anne Marie Rafferty \\ professor ${ }^{5}$, Peter Griffiths professor ${ }^{6}$, Maria Teresa Moreno-Casbas director ${ }^{7}$, Carol Tishelman \\ professor $^{8}$, Anne Scott professor ${ }^{9}$, Tomasz Brzostek professor ${ }^{10}$, Juha Kinnunen professor ${ }^{11}$, \\ Rene Schwendimann head of education ${ }^{12}$, Maud Heinen senior researcher ${ }^{13}$, Dimitris Zikos \\ researcher ${ }^{14}$, Ingeborg Strømseng Sjetne senior researcher ${ }^{15}$, Herbert L Smith professor and \\ director $^{16}$, Ann Kutney-Lee assistant professor ${ }^{1}$
}

${ }^{1}$ Center for Health Outcomes and Policy Research, University of Pennsylvania School of Nursing, Philadelphia, PA 19104, USA; ${ }^{2}$ Centre for Health Services and Nursing Research, Catholic University Leuven, Leuven, Belgium; ${ }^{3}$ Department of Health Care Management, WHO Collaborating Centre for Health Systems, Research and Management, University of Technology Berlin, Berlin, Germany; ${ }^{4}$ Department of Health Services Research and Policy, London School of Hygiene and Tropical Medicine, London, UK; ${ }^{5}$ Florence Nightingale School of Nursing and Midwifery, King's College London, London; ${ }^{6}$ School of Health Sciences, University of Southampton, Southampton, UK; ${ }^{7}$ National Spanish Research Unit, Instituto de Salud Carlos III, Ministry of Science and Innovation, Madrid, Spain; ${ }^{8}$ Medical Management Centre, LIME, Karolinska Institutet, Stockholm, Sweden; ${ }^{9}$ School of Nursing, Dublin City University, Dublin, Ireland; ${ }^{10}$ Department of Internal Diseases and Community Nursing, Faculty of Health Care, Jagiellonian University Collegium Medicum, Krakow, Poland; ${ }^{11}$ Department of Health Policy and Management, University of Eastern Finland, Kuopio, Finland; ${ }^{12}$ Institute of Nursing Science, University of Basel, Basel, Switzerland; ${ }^{13}$ Q Healthcare, Scientific Institute for Quality of Healthcare, Radboud University Medical Centre, Nijmegen, Netherlands; ${ }^{14}$ Laboratory of Health Informatics, Faculty of Nursing, National and Kapodistrian University of Athens, Athens, Greece; ${ }^{15}$ Norwegian Knowledge Centre for the Health Services, Oslo, Norway ; ${ }^{16}$ Population Studies Center, Department of Sociology, University of Pennsylvania, Philadelphia; ${ }^{17}$ Belgian Healthcare Knowledge Centre, Brussels, Belgium

\begin{abstract}
Objective To determine whether hospitals with a good organisation of care (such as improved nurse staffing and work environments) can affect patient care and nurse workforce stability in European countries.

Design Cross sectional surveys of patients and nurses.

Setting Nurses were surveyed in general acute care hospitals (488 in 12 European countries; 617 in the United States); patients were surveyed in 210 European hospitals and 430 US hospitals.

Participants 33659 nurses and 11318 patients in Europe; 27509 nurses and more than 120000 patients in the US.

Main outcome measures Nurse outcomes (hospital staffing, work environments, burnout, dissatisfaction, intention to leave job in the next
\end{abstract}

year, patient safety, quality of care), patient outcomes (satisfaction overall and with nursing care, willingness to recommend hospitals).

Results The percentage of nurses reporting poor or fair quality of patient care varied substantially by country (from $11 \%$ (Ireland) to $47 \%$ (Greece)), as did rates for nurses who gave their hospital a poor or failing safety grade ( $4 \%$ (Switzerland) to $18 \%$ (Poland)). We found high rates of nurse burnout (10\% (Netherlands) to $78 \%$ (Greece)), job dissatisfaction (11\% (Netherlands) to $56 \%$ (Greece)), and intention to leave (14\% (US) to $49 \%$ (Finland, Greece)). Patients' high ratings of their hospitals also varied considerably (35\% (Spain) to $61 \%$ (Finland, Ireland)), as did rates of patients willing to recommend their hospital (53\% (Greece) to $78 \%$ (Switzerland)). Improved work environments and reduced ratios of patients to nurses were associated with increased care quality and 
patient satisfaction. In European hospitals, after adjusting for hospital and nurse characteristics, nurses with better work environments were half as likely to report poor or fair care quality (adjusted odds ratio 0.56 , $95 \%$ confidence interval 0.51 to 0.61 ) and give their hospitals poor or failing grades on patient safety $(0.50,0.44$ to 0.56$)$. Each additional patient per nurse increased the odds of nurses reporting poor or fair quality care $(1.11,1.07$ to 1.15$)$ and poor or failing safety grades (1.10, 1.05 to 1.16). Patients in hospitals with better work environments were more likely to rate their hospital highly $(1.16,1.03$ to 1.32$)$ and recommend their hospitals $(1.20,1.05$ to 1.37$)$, whereas those with higher ratios of patients to nurses were less likely to rate them highly $(0.94,0.91$ to 0.97$)$ or recommend them $(0.95,0.91$ to 0.98$)$. Results were similar in the US. Nurses and patients agreed on which hospitals provided good care and could be recommended.

Conclusions Deficits in hospital care quality were common in all countries. Improvement of hospital work environments might be a relatively low cost strategy to improve safety and quality in hospital care and to increase patient satisfaction.

\section{Introduction}

In the face of sustained increasing pressure on health expenditures from ageing populations, rising public expectations, and the introduction of new technology, European countries have been implementing a wide range of cost containment strategies. From one perspective, these strategies have been successful. Although expenditures on health, expressed as a percentage of gross domestic product, have been rising in European countries, the rate of increase in Europe has been much slower than in the United States. The Netherlands, the highest spending European country in 2009, spends only $12.0 \%$ of their gross domestic product on health, compared with $17.4 \%$ spent in the US. In many European countries, this percentage is much lower, for example, Finland at $9.2 \%$ and the United Kingdom at $9.8 \% .^{12}$

The precise measures taken by individual countries to contain rising costs vary but many have extracted greater "efficiency" from health assets, and in particular, hospitals. These efforts have targeted patients. Average length of hospital stay has fallen substantially since 1980 , typically by about $50 \%$. Patient throughput has increased markedly in the midst of a considerable reduction in the number of beds. In addition to advances in medical science that have enabled more active treatment for people with multiple comorbidities, patients in hospital care, on average, need more intensive management. ${ }^{3}$ Another target relates to care providers. In some countries, a focus on skill mix has led to the substitution of professional nurses with health care assistants who might have minimal training. ${ }^{4}$ This possible combination of fewer trained staff and more intensive interventions raises concerns about whether, in a context of constrained expenditures, the quality of care will deteriorate as a result.

More than a decade ago, two landmark reports- the World Health Organization's The world health report $2000^{5}$ and the Institute of Medicine's Crossing the quality chasm ${ }^{6}$ - called for the realignment of incentives to balance the often competing goals of cost containment and quality improvement. Both reports concluded that responsiveness to citizens' expectations was a valued and desired outcome of health system performance. Efforts to measure patient satisfaction have thus increased, ${ }^{7}$ and in some countries, incentives have been adopted to foster patient satisfaction and patient centred care. ${ }^{89}$

Research confirms that features of the hospital work environment (such as better staffing ratios of patients to nurses, nurse involvement in decision making, and positive doctor-nurse relations) are associated with improved patient outcomes, including mortality and patient satisfaction. ${ }^{9-13}$ This association is probably due to the important role of nurses in the surveillance system of hospitals. This body of research, mostly conducted in the US, has been translated into practice and public policies in the country. For example, minimum staffing mandates for hospital nurses have been enacted in California ${ }^{14}$ and the number of hospitals with Magnet accreditation for excellence in nurse work environments has increased. ${ }^{15}$ But little evidence indicates the uptake of these research findings and evidence based best practices in Europe, even though a few country specific studies have reported similar results. ${ }^{16-19}$

Yet Europe offers an ideal setting to examine this issue. Within the broad trends described above, Europe has considerable diversity, both in the resources committed and the measures taken to contain costs. Is the same association between the hospital work environment, nurse staffing, and patient satisfaction seen in all countries? Have some countries been able to provide substantially better hospital work environments and greater patient satisfaction than others? If so, why? We report results from a study of hospital work environments and patient safety, satisfaction, and quality of care in European hospitals as reported by both nurses and patients. We obtained survey data from 12 countries in Europe and compared them with previous research, from four large US states. Our hypothesis was that hospitals with a good organisational context of care (that is, better hospital nurse staffing and nurse work environments) benefited patients and enhanced nurse workforce stability.

\section{Methods}

\section{Hospital, nurse, and patient samples}

We did a cross sectional study of 1105 general acute hospitals - 488 in 12 European countries (Belgium, England, Finland, Germany, Greece, Ireland, Netherlands, Norway, Poland, Spain, Sweden, and Switzerland), and 617 in California, Pennsylvania, Florida, and New Jersey in the US. The study included 61168 professional bedside care nurses and more than 130000 patients from participating hospitals. ${ }^{12} 20$

European data included surveys of 33659 nurses undertaken in 2009-10 in 488 study hospitals and 11318 patients in 210 of these hospitals. US data were from a 2006-7 survey of 27509 nurses in 617 participating hospitals and patient satisfaction data were obtained from more than 120000 patients in 430 of these hospitals. The same nurse and patient survey instruments were used in all countries. The processes of translation, piloting, and subsequent validation of survey instruments were rigorous. ${ }^{21}{ }^{22}$ In Europe, a key informant in each hospital was surveyed to obtain information on hospital characteristics; in the US, these data were obtained from the American Hospital Association annual survey. Ethical approval was obtained by all 13 participating universities.

Geographically representative samples of at least 30 hospitals were recruited in each country, except for: Ireland and Norway, where all hospitals were recruited; Sweden, where nearly all hospitals were included by virtue of sampling all medical-surgical nurses who were members of the Swedish Nursing Association; and the four states in the US, where nearly all hospitals were included as a result of sampling nurses from current state licensure lists. In all European countries apart from Sweden, we randomly sampled adult medical and surgical wards and surveyed all nurses providing direct care to patients in these wards; we included only fully qualified professional nurses by the standards of each country. 
The patient survey was a one day census that involved all patients able to participate and who understood one of the questionnaire languages. We surveyed nurses and patients on the same wards in Belgium, Finland, Greece, Poland, and Switzerland, and patients from subsets of wards and hospitals in Spain, Germany, and Ireland. Owing to funding constraints, England, Netherlands, Norway, and Sweden did not participate in the patient satisfaction survey. We obtained US patient satisfaction data from the Centers for Medicare and Medicaid Services' hospital compare website; submission of patient satisfaction data by US hospitals was voluntary for the years studied and thus available for a subset of hospitals. ${ }^{923}$

In Sweden, all 79 acute care hospitals were represented in the study. In the remaining European countries, 409 sampled hospitals participated in the study (64\% response rate), resulting in 488 distinct hospital facilities (web table 1). In the US, 617 (74\%) of 834 hospitals had sufficient numbers of nurse respondents for study inclusion (table $1 \Downarrow$ ). Nurse response rates in Europe averaged 62\% (33 731/54 140), and patient response rates averaged $73 \%$ (11 336/15 527) (web table 2). In the US, the nurse response rate was $39 \%$; a non-respondent survey with intensive follow-up achieving a 91\% (1176/1296) response rate revealed no response bias. ${ }^{12}$ Patient response rates were not reported for US hospitals in public data sources.

Table $2 \Downarrow$ provides data for the hospitals, nurses, and patients in the eight European countries and the US that collected patient surveys. A full discussion of the samples and survey instruments can be found elsewhere; however, the nurse and patient samples differed in two important ways. ${ }^{120}$ The hospital nurses surveyed in Europe all worked on medical-surgical units, whereas those surveyed in the US included all nurses across all unit types. Furthermore, patients in Europe were surveyed while they were still in the hospital, whereas those in the US were surveyed after being discharged. Item non-response was low $(<5 \%)$ for both patients and nurses for virtually every survey question in all countries.

\section{Key measures}

We calculated nurse staffing for each hospital from nurse surveys, as a ratio of patients to nurses on the ward on each nurse's last shift, averaged across all nurses providing direct inpatient care in the sampled wards. Lower ratios indicated more favourable staffing. Primary data for nurse staffing allowed us to minimise differences in administrative reporting methods across countries and restrict staffing measures to nurses providing direct inpatient care. We defined a "nurse" as a fully qualified professional nurse by the standards of each country.

We measured the nurse work environment using the practice environment scale of the nursing work index (revised) (PES-NWI), an internationally validated measure. ${ }^{12} 132425$ The PES-NWI measures modifiable organisational behaviours, including managerial support for nursing, nurse participation in hospital affairs, doctor-nurse relations, and promotion of care quality. We used PES-NWI subscales to measure work environment scores in hospitals in the lowest (worst) quartile, interquartile range, and highest (best) quartile. These quartiles were established separately for European and US hospitals.

We measured nurse burnout with the emotional exhaustion subscale of the Maslach burnout inventory, ${ }^{26}$ an instrument with established reliability and validity in international research. ${ }^{22}$ Other nurse outcomes and nurse reported measures were derived from survey items, as done in previous studies of US hospitals, ${ }^{10}$ to contrast between nurses who were dissatisfied or satisfied with their jobs; who intended or did not intend to leave their job in the next year; who reported that the quality of care on their ward was fair or poor rather than good or excellent; who were confident or less than confident that patients could manage their own care when discharged; and who were confident or less than confident that hospital management would resolve patient care problems.

Using an item from the Agency for Healthcare Research and Quality's hospital survey on patient safety culture, ${ }^{27}$ nurses gave their ward an overall grade on patient safety. With this information, we could compare nurses who gave poor or failing grades with those who gave excellent, very good, or acceptable grades. Nurses in Europe were also asked whether they would recommend their hospitals to family and friends.

We used the Hospital Consumer Assessment of Healthcare Providers and Systems instrument to measure patient satisfaction in Europe and the US. ${ }^{23}$ Patients rated their hospitals on a scale of 0 to 10 (best); we compared those who scored their hospital 9 or 10 points with those who scored less than 9 points. Patients indicated whether they would recommend their hospital to family and friends, an item also collected from nurses. A composite measure of satisfaction with nursing was derived from three items asking patients whether nurses always: treated them with respect, listened carefully, and explained things in a clear manner.

\section{Analysis}

Although our units of observation were mainly individuals (patients and nurses), our units of analysis were hospitals. We controlled for hospital characteristics including size, teaching status, and technology (open heart surgery or organ transplantation (or both) defined high technology hospitals). By analysing nurse outcomes, we adjusted regression estimates (odds ratios) at the hospital level for differences in the composition of nurses between hospitals and between countries (age, sex, full time employment status, and specialty) by a multilevel model structure in which nurses were nested within hospitals and countries. By analysing patient outcomes with patient data in Europe, we made similar adjustments using a multilevel model in which patients were nested within hospitals and countries. Odds ratios for US hospitals were estimated "about" the mean odds ratio using coefficients from linear regression models, because individual data were not available. Robust logistic regression with clustering provided the same result because hierarchical modelling and the results were more straightforward to interpret.

\section{Results}

Table $3 \Downarrow$ shows the difference in nurse workloads across hospitals in Europe and the US. In European countries, the average ratio of patients to nurses across hospitals (and across all shifts) ranged from 5.4 in Norway to 13.0 in Germany, and the average ratio of patient to total staff (including professional registered nurses and non-registered nurses) ranged from 3.3 in Norway to 10.5 in Germany. The staffing ratio in the US was lower (and therefore more favourable) than in any of the European countries apart from Norway; this could have been partly due to the inclusion of nurses other than medical-surgical nurses in the US sample.

We found that a substantial proportion of nurses in every country reported quality of care deficits, high nurse burnout, job dissatisfaction, and intention to leave their current positions (table $4 \Downarrow$ ). Nurses in Greece reported a particularly high level of nurse burnout, dissatisfaction, and intention to leave; nearly half described their wards as providing poor or fair quality of 
care, and almost one fifth gave their hospitals a poor or failing safety grade. In the Netherlands, nurse burnout, dissatisfaction, and intention to leave were lower than most countries, but these rates still ranged from $10 \% 19 \%$; furthermore, only $6 \%$ of nurses gave their wards a poor or failing safety grade, and $35 \%$ rated care on their wards as fair or poor. The percentage of burnt out and dissatisfied nurses in the US was close to the European median, but the percentage of US nurses intending to leave their jobs in the next year was lower than in all European countries.

Table $5 \Downarrow$ shows the percentages of patients who gave high overall ratings to their hospital. High ratings ranged from $35 \%$ in Spain to close to 60\% in the US, Switzerland, Finland, and Ireland. High patient ratings were associated with the propensity to "definitely" recommend the hospital. Variability in what both nurses and patients experienced in hospitals was, in general, even greater within countries than between countries; however, the association between nurse and patient indicators across hospitals were quite similar. The figure $\Downarrow$ shows a scatterplot for each country in which both nurses and patients reported whether they would recommend their hospital. Each point in the scatterplot is a hospital. Although the proportions of nurses and patients who would recommend their hospitals differed within countries, the association depicted - that is, a high agreement between nurses and patients as to which hospitals provided good care-was shown consistently in different countries.

We estimated the effects of nurses' practice environment and staffing on nurse outcomes and reports of quality and safety (table $6 \Downarrow$ ). We used robust logistic regression models to estimate the effects separately without controls, and used fixed within-country slopes across Europe. We also used multivariate models (also with robust standard errors) to estimate the joint influences of staffing and work environments after controlling for differences in nurses' characteristics across hospitals, differences in structural characteristics of hospitals, and unmeasured differences in outcomes across countries.

In Europe and the US, an improved work environment was associated with pronounced negative effects on every negatively scaled outcome (that is, had a favourable influence), with and without adjusting for nurse, hospital, and country characteristics. After adjusting for hospital and nurse characteristics, nurses in hospitals with better work environments were half as likely to report poor or fair care quality (Europe, adjusted odds ratio 0.56, $95 \%$ confidence interval 0.51 to 0.61 ; US, $0.54,0.51$ to 0.58 ) and to give their hospitals poor or failing grades on patient safety $(0.50,0.44$ to $0.56 ; 0.55,0.50$ to 0.61$)$.

Each additional patient per nurse increased the odds of nurses reporting poor or fair quality care (Europe, adjusted odds ratio $1.11,1.07$ to $1.15 ;$ US, $1.06,1.03$ to 1.10 ) and poor or failing safety grades $(1.10,1.05$ to $1.16 ; 1.05,1.00$ to 1.10$)$. Nurse outcomes of high burnout, dissatisfaction, and intention to leave had similar associations with effects, and the work environment effect was generally stronger than the specific staffing effect. Among countries at all levels of health expenditure, improved work environments and increased nurse workloads had similar influences (data not shown).

We used robust logistic regression models to allow for the clustering of patients within hospitals and to estimate the separate effects of different nursing factors and characteristics (table $7 \Downarrow$ ). We estimated these effects on the odds of patients rating their hospital highly ( 9 or 10 points $v<9$ points); patients indicating that they would definitely recommend their hospital; and patients responding that nurses always treated them with courtesy and respect, listened to them carefully, and explained things in a clear manner.

An improved work environment had a substantially positive effect on all three positively scaled patient measures in all countries (that is, a favourable influence). Patients in hospitals with better work environments were more likely to rate their hospital highly both in Europe (adjusted odds ratio 1.16, 95\% confidence interval 1.03 to 1.32 ) and the US $(1.18,1.13$ to 1.23$)$ and to recommend their hospital (Europe, 1.20, 1.05 to 1.37; US, $1.23,1.17$ to 1.29 ). Patients in hospitals with higher ratios of patients to nurses (that is, increased nurse workload) were less likely to rate their hospital highly $(0.94,0.91$ to $0.97 ; 0.96$, 0.94 to 0.98$)$ and to recommend their hospital $(0.95,0.91$ to $0.98 ; 0.95,0.92$ to 0.97$)$. Patients were also less likely to rate their hospital highly, recommend their hospital, and respond favourably about nurses in hospitals with increased percentages of nurses reporting only fair or poor quality care and poor or failing safety grades (table 7). Patients were less satisfied with hospitals that had higher percentages of burnt out or dissatisfied nurses or nurses who lacked confidence in management.

\section{Discussion}

\section{Summary of main results}

Despite differences in how healthcare is organised, financed, and resourced, our cross sectional data suggested that all 13 countries studied face problems of hospital quality, safety, and nurse burnout and dissatisfaction. Although nurse shortages have been moderated partly by the global economic downturn, nurses' reports of their intentions to leave their jobs in hospitals could indicate future difficulties, especially with the substantial rates seen in Europe (from 19\% in the Netherlands to $49 \%$ in Finland and Greece). In all countries, nurse staffing and the quality of the hospital work environment (managerial support for nursing care, good doctor-nurse relations, nurse participation in decision making, and organisational priorities on care quality) were significantly associated with patient satisfaction, quality and safety of care, and nurse workforce outcomes. More specifically, hospitals with good work environments and nurse staffing had improved outcomes for patients and nurses alike. Although we cannot be sure of causality because the data were cross sectional, the hospital work environment was associated with outcomes in each country.

Patients' and nurses' ratings of hospitals were similar. Whether patients rated their hospital as excellent or would recommend their hospital to other patients was associated significantly with nurses' ratings of their hospital work environment and reports of nurse staffing. Data from nurses in every country suggested a lack of confidence that hospital management would solve identified problems in patient care. Management's skepticism of nurses' complaints reflecting objective clinical observations of care quality might need to be tempered by our results, which show that nurses' assessments concur with those made independently by patients. Our data support the conclusion reached by the World Alliance for Patient Safety that organisational behaviours are important in promoting patient safety. ${ }^{28}$

\section{Differences in quality of care assessments among countries}

We noted differences in quality of care assessments among countries. Nurses' ratings of quality and job satisfaction were worst in Greece, whose health system has had severe economic difficulties and where there have been widespread protests about the government's austerity measures. Spain, which ranked third 
worst on quality, has also had austerity protests. Germany ranked second worst, and although it has not faced protests, its nursing workload is thought to have increased after the introduction of case based payment. By contrast, nurses in Ireland and Finland reported high levels of quality, although both countries have also had considerable economic downturns, whereas the good performance of Norway's well resourced health system was expected.

When we compared our findings with economic indicators published by the Organisation for Economic Co-operation and Development on each country (such as number of nurses per capita or health expenditure as a percentage of the country's gross domestic product), no clear association of nurses' and patients' views of hospital quality and safety and economic indicators were evident (data not shown). Perhaps these national level indicators did not reflect differences in hospital level investments that our study suggested could affect quality, such as better work environments and nurse staffing. The US, for example, has fewer nurses per capita than most countries in the Organisation for Economic Co-operation and Development countries ${ }^{29}$ but comparatively more nurses per patient in hospitals as shown in this study. The US has recently implemented several high profile initiatives to achieve safe nurse staffing and improve work environments. More than 20 US states have enacted or are considering to enact nurse staffing legislation, ${ }^{14}$ and Magnet accreditation promoting improved work environments has increased to almost 400 (7\%) of hospitals. Similar activity has been less apparent in Europe. One National Health Service trust in England achieved Magnet status in the past but management did not support retaining its designation. ${ }^{19}$ Magnet status is internationally recognised, with accredited hospitals in Australia, New Zealand, and Singapore, among others; however, Europe does not have a single Magnet hospital nor an equivalent recognition of nursing excellence.

\section{Potential limitations}

Our study relied on cross sectional data and therefore could not definitively establish causality, although the results recorded across countries were consistent. Furthermore, although we used similar instruments to obtain information from nurses and patients in all countries, language differences might have produced varying responses that could have affected our results. However, we used rigorous methods to verify the accuracy of translations, and content validity indexing to confirm the applicability of concepts across cultures and languages. ${ }^{20}$

Despite being able to link patients and nurses to the same hospitals to investigate how nursing characteristics affected patient and nurse outcomes across hospitals, we could not link individual patients and nurses. Furthermore, although the similarity in nurse and patient sampling in the different European countries made comparisons between these countries reasonable, the interpretation of any differences between the US and European countries should only be made cautiously, if at all. The sample of hospital nurses in the US was broader (and included non-medical-surgical nurses) than those in Europe, and the surveying of patients there was done after discharge, rather than before.

\section{Conclusions and policy implications}

Observations from our large study of different countries indicate that organisational behaviour and the retention of a qualified and committed nurse workforce might be a promising area to improve hospital care safety and quality, both nationally and internationally. Improvement of the hospital work environment can be a relatively low cost strategy on improved healthcare. Indeed, our research in the US showed that investments in better nurse staffing improved patient outcomes only if hospitals also had a good work environment. ${ }^{12}$ Best practices such as Magnet recognition are associated with successful organisational transformations..$^{15} 19$

Our results suggest that the associations between nursing and the quality and safety of hospital care are remarkably similar across Europe and in the US, even if the aggregate levels of each measure vary between countries. Thus, efforts to improve hospital work environments and quality of care in any of these countries could be effective elsewhere. Almost every country had one or more hospitals that nurses ranked as having good work environments, suggesting that this success could be replicated in additional hospitals.

We thank Tim Cheney and Ryan Lee for their analytical assistance. RN4CAST consortium: Walter Sermeus (Director), Koen Van den Heede, Luk Bruyneel, Emmanuel Lesaffre, Luwis Diya (Belgium, Catholic University Leuven); Linda Aiken (codirector), Herbert Smith, Timothy Cheney, Douglas Sloane (USA, University of Pennsylvania); Anne Marie Rafferty, Jane Ball, Simon Jones, Brian Mclntosh (UK, King's College London); Peter Griffiths (UK, University of Southampton); Juha Kinnunen, Anneli Ensio, Virpi Jylhä (Finland, University of Eastern Finland); Reinhard Busse, Britta Zander, Miriam Blümel (Germany, Technical University Berlin); John Mantas, Dimitrios Zikos (Greece, University of Athens); Anne Scott, Anne Matthews, Anthony Staines (Ireland, Dublin City University); Ingeborg Strømseng Sjetne, Christine Tvedt, Jon Helgeland (Norway, Norwegian Knowledge Centre for the Health Services); Tomasz Brzostek, Maria Kózka, Piotr Brzyski, Lucyna Przewoźniak, Anna Ksykiewicz-Dorota (Poland, Jagiellonian University Collegium Medicum, Medical University of Lublin); Teresa Moreno-Casbas, Carmen Fuentelsaz-Gallego, Esther Gonzalez-María, Monica Contreras-Moreira (Spain, Institute of Health Carlos III); Carol Tishelman, Rikard Lindqvist, Sara Runesdotter, Lisa Smeds (Sweden, Karolinska Institute); Sabina De Geest, Maria Schubert, René Schwendimann (Switzerland, Basel University); Maud Heinen, Lisette Schoonhoven, Theo van Achterberg (Netherlands, Radboud University Nijmegen Medical Centre); advisers were Martin McKee (UK, London School of Hygiene and Tropical Medicine) and Mireille Kingma (Switzerland, International Council of Nurses). See www.rn4cast.eu for additional information.

Contributors: LHA, WS, KVH, DMS, RB, MMcK, LB, AMR, PG, and AKL reviewed the literature, interpreted international data, and participated in writing this manuscript. WS and LHA codirected the parent study. All authors contributed to study design and implementation, data collection, conducted country data analyses, and interpreted national data for this paper. All authors contributed to and approved the final manuscript. LHA is the guarantor.

Funding: This research received funding from the European Union's Seventh Framework Programme (FP7/2007-2013, grant agreement no 223468) and the National Institute of Nursing Research, National Institutes of Health (R01NR004513). Funding sponsors had no role in study design, implementation, manuscript development, or decision to publish.

Competing interests: All authors have completed the Unified Competing Interest form at www.icmje.org/coi_disclosure.pdf (available on request from the corresponding author) and declare: funding from the European Union's Seventh Framework Programme and the National Institute of Nursing Research, National Institutes of Health; no financial relationships with any organisations that might have an interest in the submitted work in the previous three years; no other relationships or activities that could appear to have influenced the submitted work. 


\section{What is already known on this topic}

Staffing management accounts for a substantial portion of health expenditure

Measures to contain increasing healthcare costs globally are exerting pressures on the hospital nurse workforce that could have negative consequences for quality of care, although good evidence is lacking

\section{What this study adds}

Hospitals with good work environments and better professional nurse staffing have more satisfied patients and nurses, and evidence of better quality and safety of care

Improving hospital work environments could be an affordable organisational strategy to improve patient outcomes and retain qualified nurses providing care directly

Ethical approval: The European study protocol was reviewed and approved by the lead university, Catholic University of Leuven, Belgium. Additionally, each grantee organisation in each of the 12 participating countries received ethical approval at the institutional level to conduct patient and nurse surveys. We also obtained country level approvals to acquire patient outcomes data. US data were collected under a protocol reviewed and approved by the University of Pennsylvania Institutional Review Board.

Data sharing: No additional data available.

1 World Health Organization. European Health for All Database. WHO, 2011.

2 OECD. OECD health data 2011- frequently requested data. 2011. www.oecd.org/ document/16/0,3746,en_2649_37407_2085200_1_1_1_37407,00.html.

3 Rechel B, Wright S, Edwards N, Dowdeswell B, McKee M, eds. Investing in hospitals of the future. European Observatory on Health Systems and Policies, 2009.

4 McKee M, Nolte E, DuBois CA. Human resources for health in Europe. Open University Press, 2006.

5 World Health Organization. The world health report 2000. Health systems: improving performance. WHO, 2000.

6 Institute of Medicine. Crossing the quality chasm: a new health system for the 21 st century. National Academy Press, 2001

7 Coulter A, Jenkinson C. European patients' views on the responsiveness of health systems and healthcare providers. Eur $J$ Public Health 2005;15:355-60.

8 Pink GH, Brown AD, Studer ML, Reiter KL, Leatt P. Pay-for-performance in publicly financed healthcare: some international experience and considerations. Health $P$ ap 2006:6:8-26.

9 Kutney-Lee A, McHugh MD, Sloane DM, Cimiotti JP, Flynn F, Neff DF, et al. Nursing: a key to patient satisfaction. Health Affair (Millwood) 2009;28:w669-77.

10 Aiken LH, Clarke SP, Sloane DM, Sochalski J, Silber JH. Hospital nurse staffing and patient mortality, nurse burnout, and job dissatisfaction. JAMA 2002;288:1987-93.

11 Kane RL, Shamliyan TA, Mueller C, Duval S, Wilt TJ. The association of registered nurse staffing levels and patient outcomes: systematic review and meta-analysis. Med Care 2007:45:1195-204.

12 Aiken LH, Cimiotti J, Sloane DM, Smith HL, Flynn L, Neff D. The effects of nurse staffing and nurse education on patient deaths in hospitals with different nurse work environments. Med Care 2011;49:1047-53.

13 Friese CR, Lake ET, Aiken LH, Silber JH, Sochalski J. Hospital nurse practice environments and outcomes for surgical oncology patients. Health Serv Res 2008:43:1145-63.

14 Aiken LH, Sloane DM, Cimiotti JP, Clarke SP, Flynn L, Seago JA, et al. Implications of the California nurse staffing mandate for other states. Health Serv Res 2010;45:904-21.
15 Kelly LA, McHugh MD, Aiken LH. Nurse outcomes in Magnet and non-Magnet hospitals. JONA 2011;41:428-33.

16 Jarman B, Gault S, Alves B, Hider A, Dolan S, Cook A, et al. Explaining differences in English hospital death rates using routinely collected data. BMJ 1999;318:1515-20.

17 Rafferty A, Clarke SP, Coles J, Ball D, James P, McKee M, et al. Outcomes of variation in hospital nurse staffing in English hospitals: cross-sectional analysis of survey data and discharge records. Int J Nurs Stud 2007;44:175-82.

18 Van den Heede K, Lasaffre E, Diya L, Vleugels A, Clarke SP, Aiken LH, et al. The relationship between inpatient cardiac surgery mortality and nurse numbers and educational level: analysis of administrative data. Int J Nurs Stud 2009;46:796-803.

19 Aiken LH, Buchan J, Ball J, Rafferty AM. Transformative impact of Magnet designation: England case study. J Clin Nurs 2008;17:3330-7.

20 Sermeus W, Aiken LH, Van den Heede K, Rafferty AM, Griffiths P, Moreno-Casbas MT, et al. Nurse forecasting in Europe (RN4CAST): rationale, design and methodology. BMC Nurs 2011;10:6.

21 Bruyneel L, Van den Heede K, Diya L, Aiken L, Sermeus W. Predictive validity of the International Hospital Outcomes Study questionnaire: an RN4CAST pilot study. J Nurs Scholarsh 2009:41:202-10.

22 Poghosyan L, Aiken LH, Sloane DM. Factor structure of the Maslach burnout inventory: an analysis of data from large scale cross-sectional surveys of nurses from eight countries. Int J Nurs Stud 2009;46:894-902.

23 US Department of Health and Human Services. Hospital compare quality of care. 2011 www.hospitalcompare.hhs.gov.

24 Lake ET. The nursing practice environment: measurement and evidence. Med Care Res Rev 2007;64:104-22S.

25 Warshawsky NE, Havens DS. Global use of the practice environment scale of the Nursing Work Index. Nurs Res 2011;1:17-31.

26 Maslach C, Jackson SE. Maslach burnout inventory: manual. 2nd ed. Consulting Psychologists Press, 1986.

27 Sorra JS, Nieva VF. Hospital survey on patient safety culture. AHRQ publication no 04-0041. Agency for Healthcare Research and Quality, 2004.

28 World Health Organization. Global priorities for patient safety research. WHO, 2009.

29 Anderson GF, Hussey PS, Frogner BK, Waters HR. Health spending in the United States and the rest of the industrialized world. Health Affair 2005;23:903-13.

Accepted: 25 January 2012

\section{Cite this as: BMJ 2012;344:e1717}

This is an open-access article distributed under the terms of the Creative Commons Attribution Non-commercial License, which permits use, distribution, and reproduction in any medium, provided the original work is properly cited, the use is non commercial and is otherwise in compliance with the license. See: http://creativecommons.org/licenses/by$\mathrm{nc} / 2.0 /$ and http://creativecommons.org/licenses/by-nc/2.0/legalcode. 


\section{Tables}

Table 1| Hospitals and nurses surveyed in 12 European countries and the US. Data are number of hospitals or nurses Nurses per hospital

\begin{tabular}{lcccc} 
Country & Hospitals & Nurses & Mean (standard deviation) & Range \\
\cline { 4 - 5 } Belgium & 67 & 3186 & $48(21)$ & $8-101$ \\
\hline England & 46 & 2918 & $63(26)$ & $6-126$ \\
\hline Finland & 32 & 1131 & $35(15)$ & $7-64$ \\
\hline Germany & 49 & 1508 & $31(17)$ & $6-67$ \\
\hline Greece & 24 & 367 & $15(7)$ & $5-32$ \\
\hline Ireland & 30 & 1406 & $47(14)$ & $19-82$ \\
\hline Netherlands & 28 & 2217 & $79(41)$ & $15-161$ \\
\hline Norway & 35 & 3752 & $107(65)$ & $25-245$ \\
\hline Poland & 30 & 2605 & $87(15)$ & $55-117$ \\
\hline Spain & 33 & 2804 & $85(37)$ & $45-167$ \\
\hline Sweden & 79 & 10133 & $128(108)$ & $11-467$ \\
\hline Switzerland & 35 & 1632 & $47(17)$ & $17-95$ \\
\hline All European & 488 & 33659 & 65 & $5-467$ \\
\hline US & 617 & 27509 & $45(38)$ & $10-282$ \\
\hline Total & 1105 & 61168 & 63 & $5-467$ \\
\hline
\end{tabular}


Table 2| Patients surveyed in eight European countries and the US, with corresponding data for hospitals and nurses. Data are number of patients, hospitals, or nurses

\begin{tabular}{|c|c|c|c|c|c|}
\hline \multirow[b]{2}{*}{ Country } & \multirow[b]{2}{*}{ Total hospitals } & \multicolumn{2}{|c|}{ Patients } & \multicolumn{2}{|c|}{ Nurses } \\
\hline & & Total & Per hospital & Total & Per hospita \\
\hline Belgium & 60 & 2623 & 44 & 2866 & 48 \\
\hline Finland & 32 & 1947 & 61 & 1131 & 35 \\
\hline Germany & 12 & 244 & 20 & 504 & 42 \\
\hline Greece & 17 & 616 & 36 & 269 & 16 \\
\hline Ireland & 10 & 285 & 29 & 486 & 49 \\
\hline Poland & 30 & 4136 & 138 & 2605 & 87 \\
\hline Spain & 15 & 470 & 31 & 1181 & 79 \\
\hline Switzerland & 34 & 997 & 29 & 1593 & 47 \\
\hline All European* & 210 & 11318 & 49 & 10635 & 50 \\
\hline$\underline{\text { USt }}$ & 430 & - & - & 21001 & 49 \\
\hline Total & 640 & - & 一 & 31636 & 51 \\
\hline
\end{tabular}

*Four European countries (Sweden, England, Netherlands, Norway) did not undertake patient surveys. tUS patient data were already aggregated by hospitals. 
Table 3| Nurse staffing in 12 European countries and the US. Data are mean (standard deviation) unless stated otherwise

\begin{tabular}{lccc} 
& \multicolumn{2}{c}{ Nurse staffing ratio } & \\
\cline { 2 - 3 } Country & Patients to professional registered nurses & & \\
Belgium & $10.7(2.2)$ & $7.9(1.7)$ & 67 \\
\hline England & $8.6(1.5)$ & $4.8(0.6)$ & 46 \\
\hline Finland & $8.3(2.2)$ & $5.3(0.8)$ & 32 \\
\hline Germany & $13.0(2.3)$ & $10.5(1.6)$ & 49 \\
\hline Greece & $10.2(2.8)$ & $6.2(2.1)$ & 24 \\
\hline Ireland & $6.9(1.0)$ & $5.0(0.8)$ & 30 \\
\hline Netherlands & $7.0(0.8)$ & $5.0(0.7)$ & 28 \\
\hline Norway & $5.4(1.0)$ & $3.3(0.5)$ & 35 \\
\hline Poland & $10.5(1.9)$ & $7.1(1.4)$ & 30 \\
\hline Spain & $12.6(1.9)$ & $6.8(1.0)$ & 33 \\
\hline Sweden & $7.7(1.1)$ & $4.2(0.6)$ & 79 \\
\hline Switzerland & $7.9(1.5)$ & $5.0(1.0)$ & 35 \\
\hline US & $5.3(1.4)$ & $3.6(2.0)$ & 617 \\
\hline
\end{tabular}

${ }^{*}$ Total staff include professional registered nurses plus lesser trained care personnel. 


\begin{tabular}{|c|c|c|c|c|c|c|c|c|c|c|c|c|c|c|}
\hline \multirow{2}{*}{$\begin{array}{l}\text { Country } \\
\text { Belgium }\end{array}$} & \multicolumn{2}{|c|}{$\begin{array}{l}\text { Reported ward to } \\
\text { have poor or fair } \\
\text { quality of care }\end{array}$} & \multicolumn{2}{|c|}{$\begin{array}{c}\text { Gave ward poor } \\
\text { or failing safety } \\
\text { grade }\end{array}$} & \multicolumn{2}{|c|}{$\begin{array}{c}\text { Regarded } \\
\text { themselves to be } \\
\text { burnt out }\end{array}$} & \multicolumn{2}{|c|}{$\begin{array}{c}\text { Dissatisfied with } \\
\text { job }\end{array}$} & \multicolumn{2}{|c|}{$\begin{array}{l}\text { Intended to leave } \\
\text { their job in the } \\
\text { next year }\end{array}$} & \multicolumn{2}{|c|}{$\begin{array}{c}\text { Not confident that } \\
\text { patients can manage } \\
\text { own care after } \\
\text { hospital discharge }\end{array}$} & \multicolumn{2}{|c|}{$\begin{array}{l}\text { Not confident that } \\
\text { hospital management } \\
\text { would resolve } \\
\text { patients' problems }\end{array}$} \\
\hline & $886 / 3167$ & 28 & $199 / 3150$ & 6 & $730 / 2938$ & 25 & $680 / 3159$ & 22 & $934 / 3164$ & 30 & $1921 / 3153$ & 61 & $2518 / 3134$ & 80 \\
\hline England & $540 / 2899$ & 19 & $191 / 2895$ & 7 & $1138 / 2699$ & 42 & $1136 / 2904$ & 39 & $1261 / 2896$ & 44 & $981 / 2901$ & 34 & $1856 / 2893$ & 64 \\
\hline Finland & $141 / 1099$ & 13 & 76/1095 & 7 & $232 / 1047$ & 22 & $300 / 1114$ & 27 & $546 / 1111$ & 49 & $441 / 1098$ & 40 & $890 / 1094$ & 81 \\
\hline Germany & $526 / 1507$ & 35 & $94 / 1506$ & 6 & $431 / 1430$ & 30 & $561 / 1505$ & 37 & $539 / 1498$ & 36 & $473 / 1505$ & 31 & $879 / 1504$ & 58 \\
\hline Greece & $170 / 361$ & 47 & $61 / 358$ & 17 & $246 / 315$ & 78 & $199 / 358$ & 56 & $177 / 358$ & 49 & $231 / 358$ & 65 & $311 / 356$ & 87 \\
\hline Ireland & $152 / 1389$ & 11 & $117 / 1385$ & 8 & $536 / 1293$ & 41 & $581 / 1383$ & 42 & $612 / 1380$ & 44 & $588 / 1385$ & 42 & $872 / 1381$ & 63 \\
\hline Netherlands & $756 / 2185$ & 35 & $123 / 2187$ & 6 & $211 / 2061$ & 10 & $240 / 2188$ & 11 & $418 / 2197$ & 19 & $889 / 2195$ & 41 & $1781 / 2200$ & 81 \\
\hline Norway & $468 / 3732$ & 13 & $199 / 3712$ & 5 & $823 / 3501$ & 24 & $773 / 3729$ & 21 & $942 / 3712$ & 25 & $2097 / 3710$ & 57 & $2739 / 3698$ & 74 \\
\hline Poland & $683 / 2581$ & 26 & $463 / 2579$ & 18 & $929 / 2321$ & 40 & $663 / 2584$ & 26 & $1056 / 2387$ & 44 & $1890 / 2571$ & 74 & $2196 / 2571$ & 85 \\
\hline Spain & $897 / 2794$ & 32 & $173 / 2784$ & 6 & $787 / 2670$ & 29 & $1053 / 2786$ & 38 & $740 / 2774$ & 27 & $1554 / 2779$ & 56 & $2370 / 2767$ & 86 \\
\hline Sweden & $\begin{array}{c}2750 / 10 \\
051\end{array}$ & 27 & $\begin{array}{c}1117 / 10 \\
035\end{array}$ & 11 & 2788/9477 & 29 & $\begin{array}{c}2251 / 10 \\
027\end{array}$ & 22 & $\begin{array}{c}3418 / 10 \\
013\end{array}$ & 34 & 2833/9995 & 28 & 7308/9988 & 73 \\
\hline Switzerland & $324 / 1604$ & 20 & $71 / 1606$ & 4 & 228/1563 & 15 & $338 / 1610$ & 21 & $447 / 1623$ & 28 & $564 / 1612$ & 35 & $1216 / 1612$ & 75 \\
\hline US & $\begin{array}{c}4196 / 26 \\
316\end{array}$ & 16 & $\begin{array}{c}1628 / 26 \\
772\end{array}$ & 6 & $\begin{array}{c}9122 / 27 \\
163\end{array}$ & 34 & $\begin{array}{c}6692 / 26 \\
935\end{array}$ & 25 & $\begin{array}{c}3767 / 27 \\
232\end{array}$ & 14 & $\begin{array}{c}11449 / 25 \\
110\end{array}$ & 46 & $\begin{array}{c}15240 / 26 \\
717\end{array}$ & 57 \\
\hline
\end{tabular}


Table 5| Patient outcomes in 12 European countries and the US. Data are number of patients reporting outcome/total number of patients and percentage

\begin{tabular}{|c|c|c|c|c|c|c|c|c|c|c|}
\hline \multirow{2}{*}{$\begin{array}{l}\text { Country } \\
\text { Belgium }\end{array}$} & \multicolumn{2}{|c|}{$\begin{array}{c}\text { Rated hospital } 9 \text { or } \\
10^{\star}\end{array}$} & \multicolumn{2}{|c|}{$\begin{array}{l}\text { Would definitely } \\
\text { recommend hospital }\end{array}$} & \multicolumn{2}{|c|}{$\begin{array}{l}\text { Reported that nurses always } \\
\text { treated them with respect }\end{array}$} & \multicolumn{2}{|c|}{$\begin{array}{l}\text { Reported that nurses always } \\
\text { listened carefully to them }\end{array}$} & \multicolumn{2}{|c|}{$\begin{array}{l}\text { Reported that nurses always } \\
\text { explained things in a clear } \\
\text { manner }\end{array}$} \\
\hline & $1179 / 2510$ & 47 & $1483 / 2461$ & 60 & $1980 / 2612$ & 76 & $1515 / 2612$ & 58 & $1389 / 2603$ & 53 \\
\hline Finland & $1128 / 1862$ & 61 & $1246 / 1851$ & 67 & $1399 / 1927$ & 73 & $1116 / 1916$ & 58 & $1158 / 1919$ & 60 \\
\hline Germany & $116 / 240$ & 48 & $161 / 243$ & 66 & $181 / 241$ & 75 & $125 / 240$ & 52 & $121 / 242$ & 50 \\
\hline Greece & $253 / 597$ & 42 & $325 / 613$ & 53 & $462 / 616$ & 75 & $402 / 614$ & 65 & $240 / 614$ & 39 \\
\hline Ireland & $171 / 282$ & 61 & $206 / 278$ & 74 & $244 / 284$ & 86 & $197 / 281$ & 70 & $188 / 284$ & 66 \\
\hline Poland & $2182 / 3979$ & 55 & $2287 / 4028$ & 57 & $3135 / 4112$ & 76 & $2864 / 4116$ & 70 & $2693 / 4103$ & 66 \\
\hline Spain & $166 / 469$ & 35 & $243 / 438$ & 55 & $354 / 463$ & 76 & $298 / 464$ & 64 & $284 / 465$ & 61 \\
\hline Switzerland & $587 / 976$ & 60 & $761 / 980$ & 78 & $842 / 988$ & 85 & $693 / 987$ & 70 & $690 / 984$ & 70 \\
\hline USt & - & 59 & - & 64 & - & - & - & - & - & - \\
\hline
\end{tabular}

${ }^{*}$ On scale of $0-10$.

†Some data were not available. 


\begin{tabular}{|c|c|c|c|c|}
\hline \multirow[b]{2}{*}{ Nurse outcome } & \multicolumn{2}{|c|}{ Europe } & \multicolumn{2}{|c|}{ US } \\
\hline & $\begin{array}{l}\text { Unadjusted odds ratio (95\% } \\
\text { Cl) }\end{array}$ & $\begin{array}{l}\text { Adjusted odds ratio (95\% } \\
\text { Cl) }\end{array}$ & $\begin{array}{l}\text { Unadjusted odds ratio (95\% } \\
\text { Cl) }\end{array}$ & $\begin{array}{c}\text { Adjusted odds ratio (95\% } \\
\mathrm{Cl})\end{array}$ \\
\hline \multicolumn{5}{|c|}{ Poor or fair quality of care in ward } \\
\hline Practice environment & 0.58 (0.53 to 0.63$)$ & 0.56 (0.51 to 0.61$)$ & 0.52 (0.49 to 0.56$)$ & 0.54 (0.51 to 0.58$)$ \\
\hline Staffing & $1.11(1.08$ to 1.13$)$ & $1.11(1.07$ to 1.15$)$ & $1.2(1.16$ to 1.25$)$ & $1.06(1.03$ to 1.1$)$ \\
\hline \multicolumn{5}{|c|}{ Poor or failing safety grade in ward } \\
\hline Practice environment & $0.5(0.43$ to 0.57$)$ & $0.50(0.44$ to 0.56$)$ & 0.53 (0.48 to 0.59$)$ & 0.55 (0.5 to 0.61$)$ \\
\hline Staffing & 1.04 (1.01 to 1.08$)$ & $1.1(1.05$ to 1.16$)$ & $1.18(1.12$ to 1.23$)$ & $1.05(1$ to 1.1$)$ \\
\hline \multicolumn{5}{|l|}{ Burnout } \\
\hline Practice environment & 0.69 (0.63 to 0.76$)$ & 0.67 (0.61 to 0.73$)$ & 0.69 (0.66 to 0.73$)$ & 0.71 (0.68 to 0.75$)$ \\
\hline Staffing & $1.06(1.04$ to 1.08$)$ & $1.05(1.02$ to 1.09$)$ & $1.12(1.08$ to 1.15$)$ & $1.03(1$ to 1.06$)$ \\
\hline \multicolumn{5}{|l|}{ Job dissatisfaction } \\
\hline Practice environment & $0.63(0.57$ to 0.69$)$ & $0.52(0.47$ to 0.57$)$ & $0.58(0.55$ to 0.61$)$ & $0.6(0.57$ to 0.64$)$ \\
\hline Staffing & $1.1(1.08$ to 1.12$)$ & $1.07(1.04$ to 1.11$)$ & $1.17(1.13$ to 1.21$)$ & $1.06(1.03$ to 1.09$)$ \\
\hline \multicolumn{5}{|c|}{ Intention to leave in the next year } \\
\hline Practice environment & $0.72(0.66$ to 0.79$)$ & 0.61 (0.56 to 0.67$)$ & 0.7 (0.65 to 0.76$)$ & $0.69(0.64$ to 0.75$)$ \\
\hline Staffing & $1.04(1.01$ to 1.06$)$ & $1.05(1.02$ to 1.09$)$ & $1.1(1.05$ to 1.15$)$ & $1.03(0.98$ to 1.08$)$ \\
\hline \multicolumn{5}{|c|}{ Not confident that patients can manage own care after hospital discharge } \\
\hline Practice environment & $0.62(0.56$ to 0.69$)$ & $0.73(0.69$ to 0.78$)$ & 0.71 (0.67 to 0.75$)$ & $0.72(0.68$ to 0.77$)$ \\
\hline Staffing & $1.08(1.05$ to 1.11$)$ & $1.03(1$ to 1.05$)$ & $1.1(1.06$ to 1.13$)$ & $1.04(1.01$ to 1.07$)$ \\
\hline \multicolumn{5}{|c|}{ Not confident that hospital management would resolve patients' problems } \\
\hline Practice environment & $0.5(0.46$ to 0.54$)$ & $0.53(0.48$ to 0.58$)$ & $0.56(0.53$ to 0.59$)$ & $0.56(0.54$ to 0.59$)$ \\
\hline Staffing & 1.04 (1.01 to 1.07$)$ & $1.02(0.98$ to 1.06$)$ & 1.12 (1.09 to 1.17$)$ & 1.01 (0.98 to 1.03$)$ \\
\hline
\end{tabular}

Huber-White cluster correction used for standard errors. Controls included hospital characteristics (teaching status, high technology, bed size), nurse characteristics (age, sex, and full time employment status), specialty of unit, and country. 


\begin{tabular}{|c|c|c|c|c|c|c|}
\hline & \multicolumn{2}{|c|}{ Patient rating hospital 9 or $\mathbf{1 0}^{*}$} & \multicolumn{2}{|c|}{$\begin{array}{l}\text { Patient definitely recommending } \\
\text { hospital }\end{array}$} & \multicolumn{2}{|c|}{$\begin{array}{l}\text { Patient reporting favourable nurse } \\
\text { communication }\end{array}$} \\
\hline & $\begin{array}{l}\text { Unadjusted odds } \\
\text { ratio }(95 \% \mathrm{Cl})\end{array}$ & $\begin{array}{l}\text { Adjusted odds } \\
\text { ratio }(95 \% \mathrm{Cl})\end{array}$ & $\begin{array}{l}\text { Unadjusted odds } \\
\text { ratio }(95 \% \mathrm{Cl})\end{array}$ & $\begin{array}{l}\text { Adjusted odds } \\
\text { ratio }(95 \% \mathrm{Cl})\end{array}$ & $\begin{array}{l}\text { Unadjusted odds } \\
\text { ratio }(95 \% \mathrm{Cl})\end{array}$ & $\begin{array}{l}\text { Adjusted odds } \\
\text { ratio }(95 \% \mathrm{Cl})\end{array}$ \\
\hline \multicolumn{7}{|l|}{ Europe } \\
\hline Patient to nurse ratio & 0.91 (0.88 to 0.94$)$ & 0.94 (0.91 to 0.97$)$ & 0.9 (0.87 to 0.93$)$ & $0.95(0.91$ to 0.98$)$ & 0.98 (0.95 to 1.01$)$ & 0.99 (0.96 to 1.02$)$ \\
\hline Nurse work environment & 1.24 (1.11 to 1.38$)$ & 1.16 (1.03 to 1.32$)$ & 1.41 (1.22 to 1.62$)$ & $1.2(1.05$ to 1.37$)$ & $1.05(0.93$ to 1.19$)$ & 1.11 (1 to 1.23$)$ \\
\hline \multicolumn{7}{|l|}{ Nurse outcomest } \\
\hline $\begin{array}{l}\text { Poor or fair quality of } \\
\text { care in ward }\end{array}$ & 0.83 (0.8 to 0.87$)$ & 0.88 (0.84 to 0.92$)$ & 0.85 (0.8 to 0.89$)$ & 0.87 (0.82 to 0.92$)$ & 0.93 (0.88 to 0.97$)$ & 0.94 (0.9 to 0.98$)$ \\
\hline $\begin{array}{l}\text { Poor or failing safety } \\
\text { grade in ward }\end{array}$ & 0.9 (0.83 to 0.98$)$ & 0.85 (0.77 to 0.94$)$ & $0.79(0.73$ to 0.86$)$ & 0.85 (0.76 to 0.94$)$ & 1.06 (0.99 to 1.13$)$ & 0.93 (0.87 to 0.99$)$ \\
\hline Burnout & 0.92 (0.89 to 0.96$)$ & 0.93 (0.88 to 0.97$)$ & 0.89 (0.85 to 0.94$)$ & $0.94(0.89$ to 1$)$ & $0.97(0.93$ to 1.01$)$ & $0.95(0.91$ to 1$)$ \\
\hline Job dissatisfaction & $0.9(0.86$ to 0.94$)$ & $0.92(0.87$ to 0.96$)$ & 0.91 (0.86 to 0.97$)$ & 0.91 (0.87 to 0.96$)$ & $0.92(0.88$ to 0.96$)$ & 0.95 (0.91 to 0.98$)$ \\
\hline $\begin{array}{l}\text { Intention to leave in the } \\
\text { next year }\end{array}$ & $0.98(0.93$ to 1.04$)$ & 0.91 (0.85 to 0.98$)$ & $0.93(0.87$ to 0.98$)$ & $0.92(0.86$ to 0.98$)$ & 0.95 (0.91 to 1$)$ & 0.95 (0.91 to 0.99$)$ \\
\hline $\begin{array}{l}\text { Not confident that } \\
\text { patients can manage } \\
\text { care after hospital } \\
\text { discharge }\end{array}$ & 0.93 (0.89 to 0.97$)$ & 0.91 (0.85 to 0.97$)$ & $0.86(0.82$ to 0.89$)$ & 0.91 (0.86 to 0.98$)$ & $1.03(0.98$ to 1.07$)$ & 0.92 (0.87 to 0.97$)$ \\
\hline $\begin{array}{l}\text { Not confident that } \\
\text { hospital management } \\
\text { would resolve patients' } \\
\text { problems }\end{array}$ & 0.97 (0.92 to 1.02$)$ & $0.96(0.9$ to 1.02$)$ & 0.91 (0.85 to 0.97$)$ & 0.95 (0.89 to 1.01$)$ & 0.99 (0.93 to 1.05$)$ & 0.95 (0.9 to 0.99$)$ \\
\hline \multicolumn{7}{|l|}{ US $\neq$} \\
\hline Patient to nurse ratio & 0.95 (0.93 to 0.97$)$ & $0.96(0.94$ to 0.98$)$ & $0.93(0.91$ to 0.96$)$ & 0.95 (0.92 to 0.97$)$ & 1 (0.98 to 1.02$)$ & 1 (0.98 to 1.02$)$ \\
\hline Nurse work environment & $1.23(1.18$ to 1.29$)$ & $1.18(1.13$ to 1.23$)$ & $1.3(1.23$ to 1.37$)$ & $1.23(1.17$ to 1.29$)$ & $1.1(1.05$ to 1.14$)$ & $1.06(1.02$ to 1.1$)$ \\
\hline \multicolumn{7}{|c|}{ Nurse outcomest } \\
\hline $\begin{array}{l}\text { Poor or fair quality of } \\
\text { care in ward }\end{array}$ & 0.85 (0.83 to 0.88$)$ & 0.88 (0.86 to 0.9$)$ & 0.84 (0.81 to 0.87 ) & 0.87 (0.84 to 0.89$)$ & 0.9 (0.87 to 0.92$)$ & 0.93 (0.9 to 0.95$)$ \\
\hline $\begin{array}{l}\text { Poor or failing safety } \\
\text { grade in ward }\end{array}$ & 0.79 (0.75 to 0.84$)$ & 0.84 (0.79 to 0.88$)$ & 0.77 (0.72 to 0.82$)$ & 0.83 (0.78 to 0.88$)$ & $0.86(0.81$ to 0.9$)$ & 0.9 (0.86 to 0.94$)$ \\
\hline Burnout & $0.92(0.89$ to 0.94$)$ & $0.93(0.91$ to 0.96$)$ & $0.91(0.88$ to 0.94$)$ & $0.93(0.9$ to 0.96$)$ & $0.97(0.94$ to 0.99$)$ & $0.98(0.96$ to 1.01$)$ \\
\hline Job dissatisfaction & $0.89(0.86$ to 0.91$)$ & $0.91(0.89$ to 0.94$)$ & $0.86(0.84$ to 0.89$)$ & $0.89(0.86$ to 0.92$)$ & $0.95(0.93$ to 0.98$)$ & $0.97(0.95$ to 1$)$ \\
\hline $\begin{array}{l}\text { Intention to leave in the } \\
\text { next year }\end{array}$ & $0.88(0.85$ to 0.91$)$ & $0.92(0.89$ to 0.95$)$ & 0.87 (0.83 to 0.91$)$ & 0.91 (0.88 to 0.95$)$ & 0.9 (0.87 to 0.93$)$ & 0.95 (0.92 to 0.98$)$ \\
\hline $\begin{array}{l}\text { Not confident that } \\
\text { patients can manage } \\
\text { care after hospital } \\
\text { discharge }\end{array}$ & 0.91 (0.89 to 0.93$)$ & 0.92 (0.9 to 0.94$)$ & 0.89 (0.87 to 0.92$)$ & 0.91 (0.88 to 0.93 ) & 0.96 (0.94 to 0.98$)$ & 0.97 (0.95 to 0.98$)$ \\
\hline $\begin{array}{l}\text { Not confident that } \\
\text { hospital management } \\
\text { would resolve patients' } \\
\text { problems }\end{array}$ & 0.88 (0.86 to 0.9$)$ & 0.9 (0.88 to 0.92$)$ & $0.87(0.84$ to 0.89$)$ & 0.89 (0.87 to 0.91$)$ & 0.93 (0.91 to 0.95$)$ & 0.95 (0.93 to 0.97 ) \\
\hline
\end{tabular}

Controls included hospital characteristics (teaching status, high technology, bed size).

${ }^{*}$ On scale of $0-10$.

†For every $10 \%$ increase in outcome.

$\ddagger$ Odds ratios for US hospitals were estimated "about" the mean odds ratio by use of coefficients from linear regression models, because individual data were not available. 


\section{Figure}
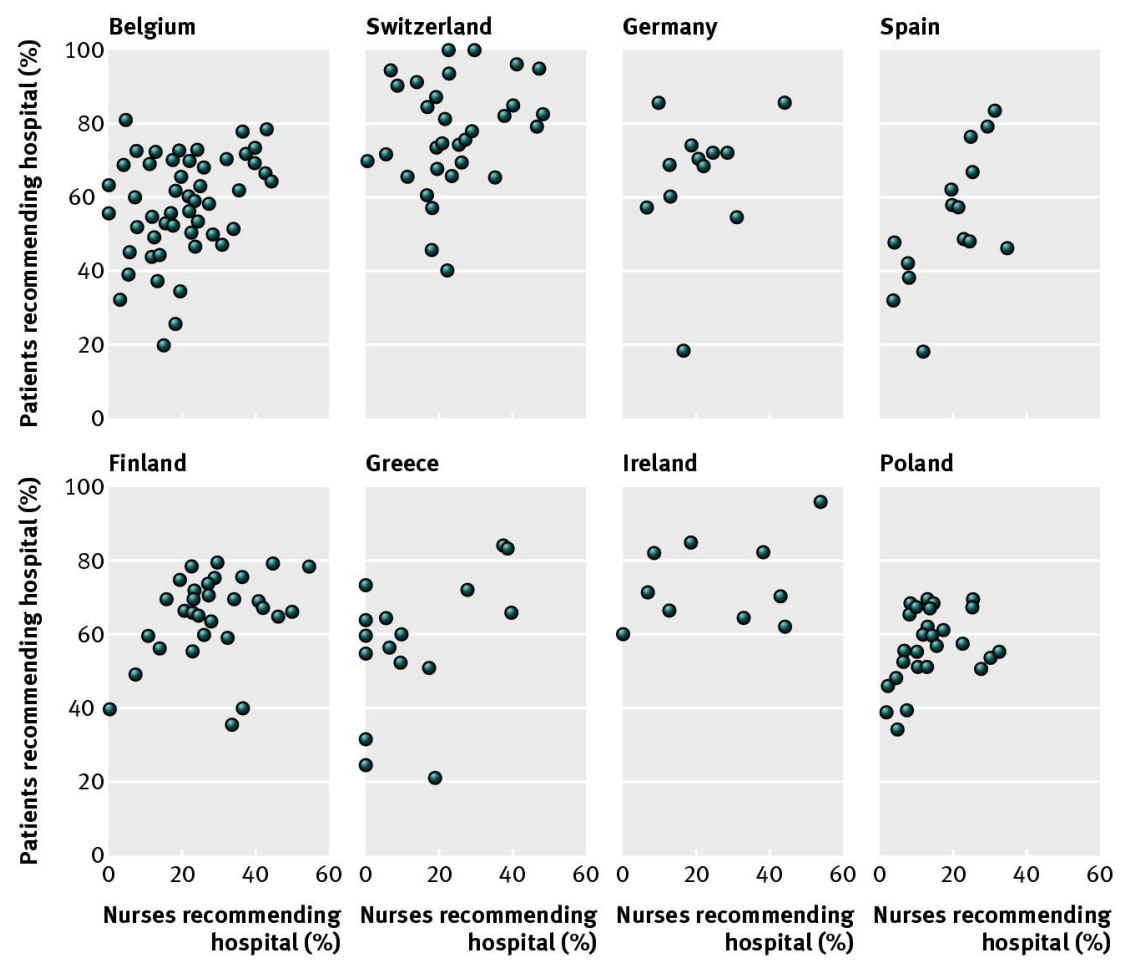

Percentages of patients and nurses recommending their hospital 